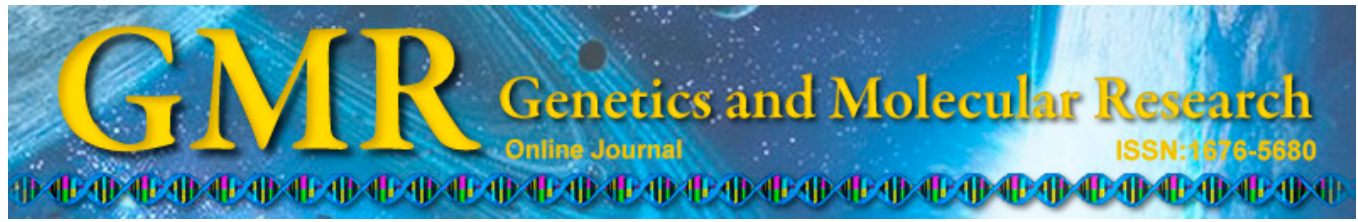

\title{
Influence of interleukin-1 $\beta$ and interleukin-6 gene polymorphisms on the development of acute pancreatitis
}

\author{
D.Z. Chi, J. Chen and D.P. Huang \\ Department of Emergency, Zhujiang Hospital, Southern Medical University, \\ Guangzhou, Guangdong Province, China \\ Corresponding author: D.P. Huang \\ E-mail: chidazhi282@163.com \\ Genet. Mol. Res. 14 (1): 975-980 (2015) \\ Received May 14, 2014 \\ Accepted October 22, 2014 \\ Published February 3, 2015 \\ DOI http://dx.doi.org/10.4238/2015.February.3.5
}

\begin{abstract}
We investigated the association between 3 main proinflammatory cytokines [interleukin (IL)-1 $\beta$ and IL-6] and the risk of acute pancreatitis. Polymerase chain reaction-restriction fragment length polymorphism was used to genotype $I L-1 \beta+3954$ $\mathrm{C} / \mathrm{T}(\mathrm{rs} 1143634)$ and $I L-1 \beta-511 \mathrm{C} / \mathrm{T}(\mathrm{rs} 16944)$ and $I L-6-174 \mathrm{G} / \mathrm{C}$ (rs1800795) and $I L-6-634 \mathrm{C} / \mathrm{G}$ (rs1800796). The genotype distributions of $I L-1 \beta+3954 \mathrm{C} / \mathrm{T}(\mathrm{rs} 1143634)$ and $I L-1 \beta-511 \mathrm{C} / \mathrm{T}$ (rs16944) and $I L-6$ $-174 \mathrm{G} / \mathrm{C}$ (rs1800795) and IL-6 -634 C/G (rs 1800796) were in HardyWeinberg equilibrium for the control group. Multivariate regression analyses showed that subjects carrying the rs 1143634 TT genotype had a significantly increased risk of acute pancreatitis, with an adjusted odds ratio (95\% confidence interval) of 2.11 (1.03-4.51). Subjects carrying the $I L-1 \beta$ rs 1143634 TT genotype had a significantly increased risk of acute pancreatitis in our Chinese population.
\end{abstract}

Key words: Acute pancreatitis; Chinese; Interleukin-1 $\beta$; Interleukin-6 


\section{INTRODUCTION}

Acute pancreatitis (AP) is a common and potentially lethal acute inflammatory process with a highly variable clinical course. AP accounts for more than 220,000 hospital admissions in the United States each year (Andersson et al., 2004). AP progresses to a severe form in approximately $10-20 \%$ of patients, resulting in systemic inflammatory response, multiple organ failure, and prolonged hospitalization with significant morbidity and mortality (Eland et al., 2000). It has been estimated that more than $20 \%$ of AP patients develop severe disease, inducing a systemic inflammatory response and multiple organ dysfunction and failure (Frossard et al., 2008). Two factors that cause AP are alcohol and gallstones, which play different roles and have different pathogenic mechanisms leading to pancreatic acinar cell damage. Alcohol abuse is the most common cause of AP in men, whereas gallstone migration into the bile duct is the main cause of AP in women (Dufour and Adamson, 2003; Schneider and Singer, 2005; Venneman et al., 2005).

Cytokines play a pivotal role in the development of AP by driving the inflammatory response, which causes tissue damage and organ dysfunction or even failure in severe cases. Therefore, an inflammatory response in AP can cause the release of reactive oxygen species, which may induce autodigestion of acinar cells (Apte et al., 2005). This can result in pancreatic necrosis and trigger the recruitment and activation of inflammatory cells (Weber and Adler, 2001; Apte et al., 2005). A previous study reported that interleukin (IL)-1 $\beta$, IL-6, and tumor necrosis factoralfa levels were increased in the serum of animals with acute pancreatitis (Grewal et al., 1994). However, whether polymorphisms of inflammatory cytokines are associated with risk of AP is unknown. Few studies have investigated the association between interleukin gene polymorphism and AP (Chen et al., 2009; Yin et al., 2013). Therefore, we investigated the association between polymorphisms of 2 main proinflammatory cytokines (IL-1 $\beta$ and IL-6) and the risk of AP.

\section{MATERIAL AND METHODS}

\section{Patients}

The diagnosis and evaluation of the severity of AP were made based on the following criteria: 1) abdominal pain characteristic of AP, 2) serum amylase and/or lipase $\mathrm{C} 3$ times the upper limit of normal, and 3) characteristic findings of AP on computed tomography scan. A total of 272 AP patients were recruited. Informed consent was obtained from patients or their relatives before enrolling in this study. A total of 272 age-matched control subjects $( \pm 5$ years of age) were recruited from among individuals who came to our hospital for a routine health check-up. For each case and control, $5 \mathrm{~mL}$ blood was collected for DNA sequencing.

Patients were assessed when they enrolled into study. Organ failure was defined when patients showed shock, pulmonary insufficiency, or renal failure.

\section{Genotyping analysis}

From all study participants, $5 \mathrm{~mL}$ venous blood was collected in ethylenediaminetetraacetic acid-coated tubes and stored at $-20^{\circ} \mathrm{C}$ until use. Genomic DNA was extracted using the TIANamp blood DNA kit (Tiangen Biotech, Beijing, China) according to manufacturer instructions. Polymerase chain reaction-restriction fragment length polymorphism was used to genotype $I L-1 \beta+3954 \mathrm{C} / \mathrm{T}$ (rs1143634) and $I L-1 \beta-511 \mathrm{C} / \mathrm{T}$ 
(rs16944) and $I L-6-174 \mathrm{G} / \mathrm{C}$ (rs1800795) and $I L-6-634 \mathrm{C} / \mathrm{G}$ (rs1800796). Primers and probes for $I L-1 \beta+3954 \mathrm{C} / \mathrm{T}$ (rs1143634) and $I L-1 \beta-511 \mathrm{C} / \mathrm{T}$ (rs16944) in $I L-1 \beta$ and $I L-6-174 \mathrm{G} / \mathrm{C}$ (rs1800795) and $I L-6-634 \mathrm{C} / \mathrm{G}$ (rs1800796) in $I L-6$ were designed using the Sequenom Assay Design 3.1 software (San Diego, CA, USA). The polymerase chain reaction was performed in a $30-\mu \mathrm{L}$ reaction solution containing $25 \mathrm{mM} \mathrm{MgCl}, 2 \mathrm{mM} 4 \mathrm{X}$ dNTPs, $20 \mu \mathrm{M}$ primers, and 5 $\mathrm{U} / \mu \mathrm{L}$ Taq DNA polymerase. The amplification reaction started at $94^{\circ} \mathrm{C}$ for $5 \mathrm{~min}$, denaturation at $94^{\circ} \mathrm{C}$ for $45 \mathrm{~s}$, annealing at $62^{\circ} \mathrm{C}$ for $60 \mathrm{~s}$, and extension at $72^{\circ} \mathrm{C}$ for $60 \mathrm{~s}$, with final extension at $72^{\circ} \mathrm{C}$ for $10 \mathrm{~min}$. Reproducibility was verified by repeat analysis of a randomly chosen subgroup of $10 \%$ of the subjects.

\section{Statistical analysis}

All statistical analyses were performed using the SPSS 16.0 (SPSS, Inc., Chicago, IL, USA) software. Continuous and categorical variables were expressed as means \pm standard deviation and $\mathrm{N}(\%)$ of study participants, respectively. Comparisons between patients and control subjects were made using the Student $t$-test and $\chi^{2}$-test. $\chi^{2}$-test was used to determine whether the genotype distribution of the 3 single-nucleotide polymorphisms (SNPs) were in Hardy-Weinberg equilibrium among controls. The association between polymorphisms in $I L$ $1 \beta$ and IL- 6 and the risk of AP were assessed using an unconditional multiple logistical regression model with estimated odds ratios (ORs) and 95\% confidence intervals (CIs). All statistical tests were 2 -sided, and a P value less than 0.05 was considered to be statistically significant.

\section{RESULTS}

The genotype distributions of $I L-1 \beta+3954 \mathrm{C} / \mathrm{T}$ (rs1143634) and $I L-1 \beta-511 \mathrm{C} / \mathrm{T}$ (rs16944) and $I L-6-174 \mathrm{G} / \mathrm{C}$ (rs1800795) and $I L-6$-634 C/G (rs1800796) were within HardyWeinberg equilibrium for the control group, with $P$ values of $0.11,0.19,0.96$, and 0.32 , respectively (Table 1). The minor allele frequencies among healthy controls were consistent with those of the Chinese population in the NCBI dbSNP databases.

Multivariate regression analyses showed that subjects carrying the rs 1143634 TT genotype had a significantly increased risk of AP, with adjusted ORs (95\%CI) of 2.11 (1.03-4.51) (Table 2). We found that subjects carrying the rs16944 AA genotype, rs1800795 CC genotype, or rs $1800796 \mathrm{CC}$ genotype had a slightly increased risk of AP, but no significant association was found between these polymorphisms; adjusted ORs (95\%CI) were $1.32(0.81-2.15), 1.88$ $(0.82-4.51)$, and $1.43(0.76-2.71)$, respectively.

\begin{tabular}{|c|c|c|c|c|c|}
\hline \multirow[t]{2}{*}{ Gene } & \multirow[t]{2}{*}{ SNP } & \multirow[t]{2}{*}{ Alleles } & \multicolumn{2}{|c|}{$\mathrm{MAF}^{1}$} & \multirow[t]{2}{*}{$\operatorname{HWE}^{2}$ (P value) in control } \\
\hline & & & Control group & From dbSNP & \\
\hline \multicolumn{6}{|l|}{$\overline{I L-1 \beta}$} \\
\hline$+3954 \mathrm{C} / \mathrm{T}$ & rs1143634 & $\mathrm{C} / \mathrm{T}$ & 0.189 & 0.1455 & 0.11 \\
\hline$-511 \mathrm{C} / \mathrm{T}$ & rs16944 & $\mathrm{G} / \mathrm{A}$ & 0.432 & 0.4651 & 0.19 \\
\hline \multicolumn{6}{|l|}{$I L-6$} \\
\hline$-174 \mathrm{G} / \mathrm{C}$ & rs1800795 & $\mathrm{G} / \mathrm{C}$ & 0.202 & 0.1850 & 0.96 \\
\hline$-634 \mathrm{C} / \mathrm{G}$ & rs1800796 & $\mathrm{G} / \mathrm{C}$ & 0.27 & 0.2897 & 0.32 \\
\hline
\end{tabular}

${ }^{1} \mathrm{MAF}=$ minor allele frequencies; ${ }^{2} \mathrm{HWE}=$ Hardy-Weinberg equilibrium. 
Table 2. Association between polymorphisms of $I L-1 \beta$ and $I L-6$ and AP risk.

\begin{tabular}{|c|c|c|c|c|c|c|c|}
\hline SNPs & & Cases $\mathrm{N}=272$ & $\%$ & Controls $N=272$ & $\%$ & Adjusted OR $(95 \% \mathrm{CI})^{1}$ & $P$ value \\
\hline \multicolumn{8}{|l|}{$\overline{I L-1 \beta}$} \\
\hline \multirow{3}{*}{ rs1143634 } & $\mathrm{CC}$ & 167 & 61.40 & 183 & 67.28 & 1.0 (Ref.) & - \\
\hline & $\mathrm{CT}$ & 78 & 28.68 & 75 & 27.57 & $1.14(0.76-1.70)$ & 0.50 \\
\hline & TT & 27 & 9.93 & 14 & 5.15 & $2.11(1.03-4.51)$ & 0.03 \\
\hline \multicolumn{8}{|l|}{$I L-1 \beta$} \\
\hline \multirow{3}{*}{ rs16944 } & GG & 82 & 30.15 & 93 & 34.19 & 1.0 (Ref.) & - \\
\hline & GA & 125 & 45.96 & 123 & 45.22 & $1.15(0.77-1.73)$ & 0.47 \\
\hline & AA & 65 & 23.90 & 56 & 20.59 & $1.32(0.81-2.15)$ & 0.25 \\
\hline \multirow{4}{*}{$\begin{array}{l}I L-6 \\
\text { rs1800795 }\end{array}$} & & & & & & & \\
\hline & GG & 159 & 58.46 & 173 & 63.60 & 1.0 (Ref.) & - \\
\hline & $\mathrm{GC}$ & 94 & 34.56 & 88 & 32.35 & $1.16(0.79-1.70)$ & 0.42 \\
\hline & $\mathrm{CC}$ & 19 & 6.99 & 11 & 4.04 & $1.88(0.82-4.51)$ & 0.11 \\
\hline \multirow{4}{*}{$\begin{array}{l}I L-6 \\
\quad \text { rs } 1800796\end{array}$} & & & & & & & \\
\hline & GG & 136 & 50.00 & 149 & 54.78 & 1.0 (Ref.) & - \\
\hline & $\mathrm{GC}$ & 106 & 38.97 & 101 & 37.13 & $1.15(0.79-1.67)$ & 0.44 \\
\hline & $\mathrm{CC}$ & 30 & 11.03 & 23 & 8.46 & $1.43(0.76-2.71)$ & 0.23 \\
\hline
\end{tabular}

${ }^{1}$ Adjusted for gender and age.

\section{DISCUSSION}

In the current study, we evaluated the effect of $I L-1 \beta+3954 \mathrm{C} / \mathrm{T}$ (rs1143634) and $I L$ $1 \beta-511 \mathrm{C} / \mathrm{T}(\mathrm{rs} 16944)$ and $I L-6-174 \mathrm{G} / \mathrm{C}(\mathrm{rs} 1800795)$ and $I L-6-634 \mathrm{C} / \mathrm{G}(\mathrm{rs} 1800796)$ on the development of AP risk. This is the first study to examine the association between the 4 SNPs and development of AP. We showed that the rs 1143634 polymorphism was marginally associated with AP risk. Therefore, our findings indicated that the identification of SNPs affecting gene function or expression and thus contribute to the risk of AP is valuable for predicting individual risk and understanding the pathogenesis of developing AP.

ILs are members of the inflammatory cytokine family and play important roles in the inflammatory response and immune system regulation. Previous studies have reported that increased secretion of inflammatory cytokines, including IL-1 $\beta$, IL-6, IL-8, and IL-10, play key roles in promoting the pathological process of AP (de Beaux et al., 1996; Berney et al., 1999; Wereszczynska-Siemiatkowska et al., 2002, 2003). The serum levels of inflammatory cytokines can be regulated by the transcriptional level (Berney et al., 1999; WereszczynskaSiemiatkowska et al., 2002, 2003). Previous clinical studies have shown that polymorphisms in the $I L$ promoter region are correlated with inflammatory cytokines gene transcription and their secretion (Berney et al., 1999; Wereszczynska-Siemiatkowska et al., 2002, 2003). Therefore, genetic polymorphisms in inflammatory cytokines may influence the development and pathological process or severity of AP.

Several previous studies have investigated the associations between genetic polymorphisms in inflammatory cytokines and AP risk, but results have been inconsistent (Smithies et al., 2000; Sargen et al., 2000; Powell et al., 2001; Zhang et al., 2005; Hofner et al., 2006; Chen, 2007). In a study conducted in England, Smithies et al. (2000) found that IL-1RN could determine the severity of AP and susceptibility to idiopathic AP, but no significant association was found between $I L-1 \beta$ polymorphism and AP risk in a British population. In another study in a British population, Sargen et al. (2000) reported that the tumor necrosis factor and $I L-10$ gene polymorphisms have no role in the determination of disease severity or susceptibility to acute pancreatitis (Sargen et al., 2000). In another study conducted in the United Kingdom, Powell et al. (2001) observed that there was no significant association between $I L-1 R A$ genetic 
polymorphisms and AP risk. Chen (2007) suggested that the $I L-6-174 \mathrm{G} / \mathrm{C}$ and $-634 \mathrm{C} / \mathrm{G}$ polymorphisms were not associated with AP risk among Chinese subjects, and no significant association was found between $I L-1 \beta-511 \mathrm{C} / \mathrm{T}$ polymorphism and AP risk. However, other studies reported different results. In a study conducted in China, Zhang et al. (2005) reported that the $I L-10-1082 \mathrm{G}$ allele plays a key role in the development of severe AP patients to septic shock, but genetic factors of IL-1 $\beta+3$ 594T, IL-10-1082G, and CD14-159T were not associated with disease severity or AP development. Hofner et al. (2006) reported that the $I L-8-251$ A allele was associated with an increased risk of AP in a Hungarian population. In our study, we found that subjects carrying the $I L-1 \beta$ rs 1143634 TT genotype had a significantly increased risk of AP. This discrepancy may be explained by differences in ethnicities, source of control subjects, sample size, and by chance. Further studies are needed to confirm the association between IL polymorphisms and AP risk.

The current study has several limitations. First, the study was conducted in 1 hospital in China, and the sample may not represent other populations. However, the allele frequencies in controls were similar to minor allele frequencies in a Chinese population from the NCBI reference assembly, indicating that the control subjects may represent the general population in China. Second, the number of cases and control subjects was relative small. The relatively small sample size may decrease the statistical power for identifying differences between groups. Therefore, further large sample size studies are greatly needed to confirm their association.

In summary, this study first reported that subjects carrying IL-1 $\beta$ rs 1143634 TT genotype had a significantly increased risk of AP in a Chinese population. The IL-1 $\beta$ rs 1143634 polymorphism may be used as a diagnostic biomarker for AP. Further large studies are needed to confirm the role of genetic polymorphisms in inflammatory cytokines in AP development.

\section{REFERENCES}

Andersson R, Andersson B, Haraldsen P, Drewsen G, et al. (2004). Incidence, management and recurrence rate of acute pancreatitis. Scand. J. Gastroenterol. 39: 891-894.

Apte MV, Pirola RC and Wilson JS (2005). Molecular mechanisms of alcoholic pancreatitis. Dig. Dis. 23: 232-240.

Berney T, Gasche Y, Robert J, Jenny A, et al. (1999). Serum profiles of interleukin-6, interleukin-8, and interleukin-10 in patients with severe and mild acute pancreatitis. Pancreas 18: 371-377.

Chen XQ (2007). A study on the association between the interleukin- $1 \mathrm{~b}$, interleukin- 6 gene polymorphisms and the condition of patients with acute pancreatitis. Master's thesis, Fujian Medical University, 1-49.

Chen XQ, Huang HG, Zhou YN, Li Y, et al. (2009). The study of the relationship between interleukin gene polymorphism and the morbidity of patients with acute pancreatitis. Zhongguo Wei Zhong Bing Ji Jiu Yi Xue 21: 99-102.

de Beaux AC, Goldie AS, Ross JA, Carter DC, et al. (1996). Serum concentrations of inflammatory mediators related to organ failure in patients with acute pancreatitis. Br. J. Surg. 83: 349-353.

Dufour MC and Adamson MD (2003). The epidemiology of alcohol induced pancreatitis. Pancreas 27: 286-290.

Eland IA, Sturkenboom MJ, Wilson JH and Stricker BH (2000). Incidence and mortality of acute pancreatitis between 1985 and 1995. Scand. J. Gastroenterol. 35: 1110-1116.

Frossard JL, Steer ML and Pastor CM (2008). Acute pancreatitis. Lancet 371: 143-152.

Grewal HP, Kotb M, el Din AM, Ohman M, et al. (1994). Induction of tumor necrosis factor in severe acute pancreatitis and its subsequent reduction after hepatic passage. Surgery 115: 213-221.

Hofner P, Balog A, Gyulai Z, Farkas G, et al. (2006). Polymorphism in the IL-8 gene, but not in the TLR4 gene, increases the severity of acute pancreatitis. Pancreatology 6: 542-548.

Powell JJ, Fearon KC, Siriwardena AK and Ross JA (2001). Evidence against a role for polymorphisms at tumor necrosis factor, interleukin-1 and interleukin-1 receptor antagonist gene loci in the regulation of disease severity in acute pancreatitis. Surgery 129: 633-640.

Sargen K, Demaine AG and Kingsnorth AN (2000). Cytokine gene polymorphisms in acute pancreatitis. JOP 1: 24-35. 
Schneider A and Singer MV (2005). Alcoholic pancreatitis. Dig. Dis. 23: 222-231.

Smithies AM, Sargen K, Demaine AG and Kingsnorth AN (2000). Investigation of the interleukin 1 gene cluster and its association with acute pancreatitis. Pancreas 20: 234-240.

Venneman NG, Renooij W, Rehfeld JF, VanBerge-Henegouwen GP, et al. (2005). Small gallstones, preserved gallbladder motility, and fast crystallization are associated with pancreatitis. Hepatology 41: 738-746.

Weber CK and Adler G (2001). From acinar cell damage to systemic inflammatory response: current concepts in pancreatitis. Pancreatology 1: 356-362.

Wereszczynska-Siemiatkowska U, Mroczko B and Siemiatkowski A (2002). Serum profiles of interleukin-18 in different severity forms of human acute pancreatitis. Scand. J. Gastroenterol. 37: 1097-1102.

Wereszczynska-Siemiatkowska U, Dabrowski A, Siemiatkowski A, Mroczko B, et al. (2003). Serum profiles of E-selectin, interleukin-10, and interleukin-6 and oxidative stress parameters in patients with acute pancreatitis and nonpancreatic acute abdominal pain. Pancreas 26: 144-152.

Yin YW, Sun QQ, Feng JQ, Hu AM, et al. (2013). Influence of interleukin gene polymorphisms on development of acute pancreatitis: a systematic review and meta-analysis. Mol. Biol. Rep. 40: 5931-5941.

Zhang DL, Zheng HM, Yu BJ, Jiang ZW, et al. (2005). Association of polymorphisms of IL and CD14 genes with acute severe pancreatitis and septic shock. World J. Gastroenterol. 11: 4409-4413. 